\title{
Pensamiento y mensaje en Pedro Henríquez Ureña
}

$\prod_{\text {hatándose de Pedro Henríquez Ureña no puedo rehuir, }}^{\text {hasta cierto punto, el tono personal y autobiográfico. }}$ Fue mi vida, como en la de tantos otros jóvenes de América, una fuerza conformadora y orientadora. Fue el maestro con quien tuve la envidiable fortuna de mantener por más de veinte años, hasta su muerte, una entrañable amistad. $Y$ lo que aprendí de él, lo aprendí en el trato cotidiano, más que en la lectura de sus obras. Aprendí de él a tomar en serio el oficio de escritor: bajo su implacable lápiz rojo fue cobrando forma mi prosa adolescente. Aprendí de él, también, casi todo lo que sé de literatura.

En sus clases, en sus conferencias, en la conversación -más que en sus libros - iba dando Don Pedro a sus discípulos, a sus amigos, los grandes esquemas, las categorías, los conceptos fundamentales de la estética y la historia literarias. Su conversación bajaba muchas veces al nivel de la anécdota curiosa, del dato desconocido, de la fecha precisa: su memoria era prodigiosa. Pero nunca se quedaba allí: ascendía siempre al plano de las ideas.

No sólo de literatura hablaba Don Pedro. La literatura, con ser su principal pasión, no estaba divorciada, para él, del cuerpo total de la cultura y de la historia. Era, a lo sumo, el vasto litoral de un continente cuyas grandes planicies $y$ ríos y montañas y mesetas, también había explorado. La literatura se prolongaba para Don Pedro en pintura, en música, 
en arquitectura, en historia, en política, en sociología, en ciencia, en filosofía.

\section{DEL ESPIRITU FILOSOFICO}

Estaba penetrado, en verdad, de espíritu filosófico. Al menos, en el sentido en que él mismo lo definía en uno de sus escritos juveniles; como el espíritu capaz de abarcar con visión propia e intensa los conceptos del mundo, de la vida, de la sociedad y de analizar los detalles y los extraños paralelismos de la evolución histórica y artística. ${ }^{1}$

Fue Don Pedro, sin quererlo, - porque secretamente me tenía reservado otro destino- quien impulsó mi primer interés por la filosofía. Promotor de vocaciones ajenas, mató en sí mismo, sin embargo, algunas de sus mejores posibilidades. Pocas inteligencias tan bien dotadas como la suya para el pensamiento puro. Lo prueban sus estudios filosóficos, escritos antes de los veinticinco años, y en los cuales, a la claridad de ideas y de expresión, unía -como siempre-la mejor información y la más reciente.

Don Pedro fue el primero que en nuestra América expuso las ideas de William James, cuando apenas empezaban a conocerse en Europa $;^{2}$ y uno de los primeros que señaló los elementos pragmatistas del pensamiento de Nietzsche ${ }^{3}$. Fue también el primero que en nuestros países hizo una crítica a fondo, comprensiva y superadora, del positivismo, cuyo imperio dogmático se había extendido por más de cuarenta años a todos los niveles de la vida intelectual hispanoamericana. Con motivo del ciclo de conferencias que sobre el positivismo venía pronunciando Antonio Caso en la Escuela Preparatoria de México, en 1909, Don Pedro publicó dos artículos en los que colocaba aquel movimiento dentro de su verdadero marco histórico, como una corriente de pensamiento que pertenecía ya al pasado. ${ }^{4}$

1 Cf. Horas de Estudio (París, Ollendorf, 1910), p. 292.

2 Con la posible excepción, quizá, de Carlos Vaz Ferreira, quien, por la misma época, exponia y criticaba el pragmatismo en sus cursos universitarios.

3 Cf, Op. cit., pp. 61-74.

Op. cit., pp. $13-60$. 
Esos artículos eran, de hecho, rectificaciones críticas a algunos de los conceptos expresados por Caso en sus conferencias. (Llevado por la amistad, y por la virtud de un magisterio que todos reconocían y acataban, Don Pedro asumió muchas veces el papel, nunca grato, de censor público de la obra de sus amigos y, por supuesto, de sus discípulos. Yo mismo sufrí alguna vez su enérgica censura. Censura enérgica sí, pero generosa, no para acallar o suprimir, sino para restablecer la verdad y favorecer el libre desarrollo del pensamento legítimo. Don Pedro fue, por eso, la conciencia vigilante de varias generaciones en Hispanoamérica, comenzando por la suya). Caso, en sus conferencias de la Escuela Preparatoria, mostraba, todavía, una actitud ambigua y temerosa frente al positivismo de Comte, doctrina dominante, oficial, en el México de aquellos años. Don Pedro lo censuró, precisamente por invertir el papel histórico de Comte, a quien presentaba como un gran renovador, como el punto de máximo desarrollo en el pensamiento del como el punto de máximo desarrollo en el pensamiento del siglo XIX.

Los reparos críticos de Don Pedro debieron influir poderosamente en la evolución intelectual de Caso, quien se convirtió, muy pronto, en uno de los portavoces autorizados de la reacción antipositivista. Influyó, además, en otros espíritus afines contribuyendo, de modo decisivo, al cambio intelectual que se operó, después de 1910, en toda Hispanoamérica.

\section{DEL ESPIRITU CRITICO}

A pesar de su buen comienzo, Don Pedro no persistió en el camino de la filosofía. De la filosofía, se entiende, en el sentido estricto del término. Desistió, también, de la literatura de creación en la que había alcanzado buenos logros. Quiso permanecer en el terreno mucho más árido de la crítica, de la historia literaria, de la investigación filológica, de la bibliografía, de la erudición.

A través de su obra escrita, sin embargo, se descubre la unidad de su pensamiento: el mismo espíritu filosófico que reflejaba en su conversación o en sus clases. Podrá parecer ex- 
traño a quienes sólo conozcan sus trabajos más técnicos, como La versificación irregular en la poesía castellana, pero no a quienes estén familiarizados con sus estudios críticos. En ensayos y artículos breves, en reseñas, notas bibliográficas y conferencias, fue expresando Don Pedro su visión personal, vasta y sintética, orgánica y profunda, del mundo, de la vida, de la sociedad, de la historia. Casi siempre de un modo elíptico; a veces, en las entreíneas. No escribió mucho, pero todo lo que escribió fue sólido, denso, rico en sustancia intelectual.

Dominaba, a un mismo tiempo, el arte de la miniatura y del fresco monumental. Le gustaba exhibir su asombrosa erudición y hasta tenía el virtuosismo de hacer de ella un recurso estilístico, como cuando caracterizaba una época, un movimiento, una tendencia, un estilo, mediante la enumeración, brevemente anotada, de nombres, títulos, datos, cualidades, circunstancias. Recuérdense, por ejemplo, algunos de sus catálogos de plantas y palabras indígenas, tan llenos de color y de significación. Pero su obra, como su prosa, está penetrada de un riguroso sentido de arquitectura y equilibrio: se destacan los volúmenes, las líneas de desarrollo, en estricta perspectiva. El detalle no perturba la visión de la totalidad.

La obra de Don Pedro prueba, una vez más, que el gran crítico y el verdadero historiador de la literatura no trabajan primariamente con datos y fechas, sino con ideas. Demuestra, en suma, que el crítico y el historiador deben ser, ante todo, pensadores.

\section{DEL ESPIRITU ILUSTRADO}

El pensamiento de Don Pedro se correspondía con su temperamento y era la expresión directa de su entera personalidad. Pese a sus lecturas clásicas y a su admiración juvenil por la antigüedad helénica, su inteligencia no era la de un humanista tradicional, sino más bien la de un ilustrado del siglo XVIII. Tenía demasiados intereses puestos en la realidad presente; estaba vuelto hacia el futuro, más que hacia el pasado. $\mathrm{Y}$ creía, como los hombres de la Ilustración, en el progreso moral, en la educación y en la ciencia. 
Varias veces, en acto de confesión íntima, había expresado su agnosticismo. En una ocasión, tentado por el demonio sofístico que llevo dentro de mí, le pregunté: "¿Si no cree usted en Dios, Don Pedro, cómo es que cree en la existencia de un universo con sentido?" Sonrió irónicamente, a sabiendas de que me contestaba con una finta, y dijo: "Por pura fe animal, como Santayana". Pero la fe animal es un sustituto eufemístico del escepticismo y Don Pedro no era escéptico: estaba penetrado de una inmensa fe racional. Fe, primero, en las capacidades naturales del hombre. Lo animaba no sólo la creencia roussoniana de que el hombre es naturalmente bueno; creía, además, en el sentido natural de la belleza. "El buen gusto es natural, el mal gusto es adquirido", era uno de sus axiomas estéticos. De ahí su interés constante por el arte indígena y popular y su desprecio por la vulgaridad de la cultura industrializada.

No era, sin embargo, un romántico exaltador de los impulsos primitivos. Como buen ilustrado, sólo confiaba en la inteligencia y en el esfuerzo sostenido por expresar, en formas claras y comunicables, la secreta riqueza de la imaginación y la sensibilidad espontáneas. La originalidad, en todo caso, era el fruto de una larga disciplina.

Discutiendo, en 1909, el problema de la expresión original en la literatura hispanoamericana, afirmaba: "Sólo cuando logremos dominar la técnica europea podremos explotar con éxito nuestros asuntos"5. Años más tarde, en plena madurez, al discutir las distintas fórmulas del americanismo literario decía: “... no hay secreto de la expresión sino uno: trabajarla hondamente, esforzarse en hacerla pura, bajando hasta la raíz de las cosas que queremos decir: afinar, definir, con ansia de perfección"'.

La expresión madura, genuina, original de nuestra América - en la literatura, en el arte, en la filosofía - fue uno de los temas que más le preocuparon porque veía en ella uno de los modos de la salvación: por la voz, por la forma, por la palabra, por el logos, por el espíritu. p. 32 .

5 Op. cit., p. 207.

6. Cf. Seis ensayos en busca de nuestra expresión (Buenos Aires, Babel, 1928), 


\section{DEL ESPIRITU UTOPICO}

Mucho más importante que el logro de la perfección estética o intelectual, sin embargo, era para Don Pedro la realización de la justicia. Le oí decir muchas veces que el ideal de justicia estaba antes que el ideal de cultura. $Y$ nada le irritaba tanto como el espectáculo de la injusticia. Eran las únicas ocasiones en que aquella cabeza naturalmente fría se encendía en pasión indignada. Sospecho que si en algunos momentos le irritaba también el error era por lo que suele tener de injusto y de inmoral.

De su voluntad de justicia provenía su afán utópico. Aún recuerdo vivamente el asombro que me produjo, siendo yo todavía adolescente, oírle decir en clase que las utopías no eran para ser soñadas, sino para ser realizadas; que la utopía no era un puro juego de la imaginación, sino una de las grandes creaciones espirituales de Grecia, que había legado al mundo occidental, con ella, la inquietud de la perfección infinita. Sólo mucho más tarde comprendí la sustancia ética, la gran trastienda moral, que tenía en él este pensamiento: la utopía como deber.

Su entusiasmo americanista -uno de los grandes entusiasmos de su juventud, que atenuó, pero nunca apagó la desilusión de los años maduros - estuvo constantemente alimentado por la convicción de que América debía y tenía que ser el continente de la utopía. Continente utópico que fue para la imaginación de muchos europeos, casi desde el momento mismo del descubrimiento. $\mathrm{Y}$ el primer gran ensayo de realización utópica en la historia había sido, precisamente, los Estados Unidos: el país donde se había intentado la creación de un nuevo orden fundado en la libertad, la igualdad y la justicia. No creía, sin embargo, que los Estados Unidos hubieran sido fieles a ese gran ideal utópico. Su esperanza -muchas veces desesperanzada - se volvía, por eso, hacia la América hispánica. A pesar de las disensiones estériles, de las tiranías agostadoras, de los nacionalismos enervantes -o quizás por eso mismo - nunca perdió la fe, o no quiso perderla, en el destino de nuestra América. Sostenía que la unidad de nuestra historia debiera llevarnos, por encima de las diferencias regionales y nacionales, a constituir una magna patria. 
La desunión política de nuestros pueblos significaba el desastre, como aconteció con las ciudades de la Grecia clásica, o con las repúblicas italianas del Renacimiento.

\section{DEL ESPIRITU AMERICANO}

La realización de nuestra utopía no debía tener, sin embargo, un límite en sí misma. No se trataba de acumular poder por el gusto del poder, ni de crear un nuevo imperio, fuerte y temible. Eso era plagiar una vez más la historia. Si la magna patria había de unirse, debía unirse para la justicia, para crear una sociedad nueva donde no se conocieran, ni el despotismo, ni la explotación, ni la miseria, ni la esclavitud. El ideal no podría alcanzarse, sin embargo, por la única vía de la reforma social y de la justicia económica. Para Don Pedro, la "plena emancipación del brazo y de la inteligencia", tenía que ser, ante todo, una empresa espiritual en la que colaboraran todos los hombres de buena voluntad. Eso fue quizás el sentido último de su mensaje

Fiel a su actitud racionalista, Don Pedro creía en el poder de las ideas. Pero no de las ideas abstractas, sino de las ideas encarnadas en los hombres. De ahí su preferencia por el método socrático, por el comercio directo de ideas entre maestros y discípulos. Era el único modo eficaz de prolongar, en el futuro, la genealogía moral de nuestros pueblos de América. Afirmaba que no debíamos desesperar mientras hubiese en ellos diez hombres justos que buscasen el bien. Y había levantado en su conciencia una especie de panteón invisible en el que honraba, cada día, la memoria de sus héroes preferidos: Sarmiento, Hostos, Martí, Rodó. De todas las lecciones que de él recibí ésta fue la más importante: sentir nuestra América como una comunidad moral, incesantemente renovada, de hombres de buena voluntad que creen en la utopía y trabajan por realizarla.

\section{ANÍBAL SÁNChEZ REULET \\ Unión Panamericana, Washington, D. C.}

7 P. Henriquez Ureña expuso estas ideas en dos conferencias que han sido recogidas, después de su muerte, en el volumen titulado Plenitud de América (Buenos Aires, Peña-Del Giudice, 1952). 
